\title{
Design and Development of Hybrid Converter for Marine Applications
}

T. Sasilatha

Dean \& Professor, Department of EEE, AMET

Deemed to be University, Chennai, India

D. Lakshmi

Associate Professor, Department of EEE, AMET

Deemed to be University, Chennai, India

R. Rajasree

Assistant Professor, Department of EEE, AMET

Deemed to be University, Chennai, India

J.K. Vaijayanthimala

Research scholar, Department of EEE, AMET

Deemed to be University, Chennai, India

P. Siva

PG Research scholar, Department of EEE, AMET

Deemed to be University, Chennai, India

\section{Abstract}

Recently, there has been an increase in the growth and advancement of electric propulsion in marine electrical drives. A maximum amount of energy is utilized by ships for propulsion drives. To be aware of it and develop an optimized structure to improve the effectiveness of the propulsion system with power consumption is necessary. The proposed paper aims to develop a model and perform functional analysis as per the above understanding and requirements. The factors considered include greenhouse gas emissions, $\mathrm{CO} 2$ emissions, environmental aspects, and the availability of non-renewable resources, which leads to the introduction of renewable energy as a replacement method of power generation. For this work, two different renewable sources, such as solar and wind energy, were chosen. The combination of these two resources can manipulate the voltage and satisfy the load in a desirable way. For voltage improvement, a high gain converter with a minimal number of active and passive components is selected. This system adopts a storage system to meet the needs in the future. The inverter switches are controlled by the recommended control algorithm, which can balance and provide adequate power towards the drive by a feedback control loop. The 
speed of propulsion in the drive is adjusted by the induction motor coupled with the propeller. The analytical study of the proposed system is carried out in MATLAB software. The simulation study revealed the effectiveness of this modern optimization technique.

Keywords: Renewable Energy, Propeller, MPPT optimization, PI controller, Buck Boost Converter

\section{Introduction}

Propulsion is used to propel the vessel ahead. This has been going on for a long time in the traditional manner. Prior to the twenty-first century, most ships used diesel engines for propulsion [1]. A few years ago, fossil fuels became a key resource for power production all over the world, resulting in pollution and a high total cost. Electric propulsion is used in order to focus on capital costs, fuel requirements, and the environment [2]. These factors draw attention to renewable energy sources such as solar, wind, hydro, tidal, geothermal, and others. Electricity generated by wind and solar has surpassed all other renewable energy sources in recent years [3-4]. This situation is playing out all across the world; China has taken the lead in installing 35 percent of the world's wind energy. Manufacturers of wind turbines throughout the world, such as Gold Wind, Vestas, Suzlon, General Electric, and Siemens Gamesa, have been attempting to build massive wind turbines with a capacity of 10-15 MW. The arrangement of the wind turbine and power electronic converters determines fullspeed, semi-speed, and low-speed operation.

For wind energy conversion systems (WECS), there are two types of power electronic conversions: AC-AC and AC/DC, DC/DC, DC/DC \& DC/AC. Based on the magnitude of voltage produced by the generator, it is further divided into two types: medium and low voltage converters [5]. Low-voltage conversion systems are only suited for wind turbines up to $3 \mathrm{MW}$, while medium-voltage conversion systems are acceptable for wind turbines over $3 \mathrm{MW}$. Based on solar irradiation and temperature, photovoltaic systems generate direct current (DC) power. Because each solar cell can only provide $0.5-0.6 \mathrm{~V}$, solar cells are coupled in series and parallel to increase power production. Due to its decreasing cost over time, environmentally beneficial character, and renewability, researchers have been more interested in the electricity generated by photovoltaic arrays [6]. The ability to achieve sufficient torque without compromising pitch angle is the most important consideration when choosing electric propulsion. There will be perfect redundancy in this type of propulsion.

Section II dealt with the overall study of the proposed method. The circuit configuration and the approach used to utilize the energy produced by those two renewable resources are described in section III. The charging and discharging of the battery interfaced with the converter is explained. The section IV reviewing peak current mode control technique, used in the feedback control loop to improve the 
system performance, is visualized. The Simulink study of the proposed study and the output attained from the converter are reviewed in Section $\mathrm{V}$. The effectiveness of the proposed study and its impact in the future are depicted in section VI.

\section{Proposed Methodology}

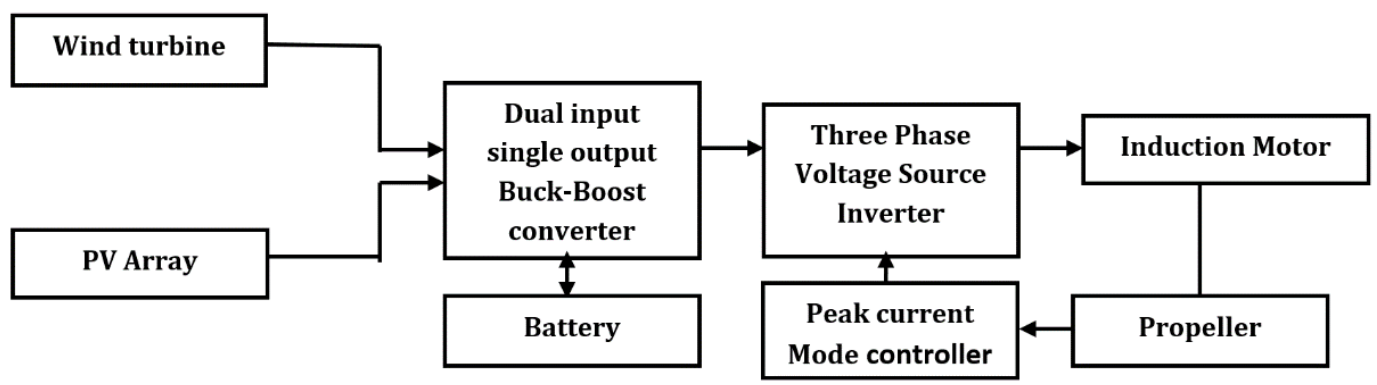

Fig.1. Block diagram of proposed system

The overall structure of the proposed methodology is shown in figure 1. The sources, such as wind turbines and PV arrays, are used in this study. When sunlight is available, the PV array generates an abundant amount of energy. Wind energy is utilized by wind turbines to supply electricity continuously. If any failure happens in any one of the generating stations, the remaining resources can manage it. The major factors which will limit voltage generation from both resources, such as solar panels, are shading, change in climatic conditions, a wide range of change in wind speed, area of the rotor, wind density, etc. Here, the role of the converter is a much needed factor. The energy gained from both sources is transmitted towards a dual input, single output buck-boost converter. Then it is stored in the battery. Whenever the generated voltage is said to be high, the converter steps down the voltage and fulfills the battery. In any condition, if the load faces voltage lag, the converter boosts the voltage received from stored energy in the battery. This is how the converter action is performed. Further, the received energy is converted into $\mathrm{AC}$ by a three-phase inverter to satisfy the load [7]. The shaft interlinks the induction motor with the propeller. The peak current mode controller receives feedback from the propeller and alters the switching cycle to improve the functionality of the inverter.

\section{Proposed converter}

The circuit configuration of the proposed converter is represented in figure $2 . \mathrm{T}_{1}$ and $\mathrm{T}_{2}$ switches are bidirectional conduction and bidirectional blocking (BCBB) switches in this configuration [8]. The diodes $\mathrm{D}_{1}$ and $\mathrm{D}_{2}$ offer freewheeling of load current. Two input sources are connected to the basic converter circuit, which consists of two switches, $\mathrm{T}_{3}$ and $\mathrm{T}_{4}$, as well as an inductor and capacitor, which is then connected to the load. The combination of switches $\mathrm{T}_{1}$ and $\mathrm{T}_{2}$ allows the converter to operate in various states. Switch $\mathrm{T}_{3}$ enables Buck-Boost functionality, while Switch $\mathrm{T}_{4}$ enables bidirectional operation of the DC/DC converter. The input sources, $E_{1}$ and $E_{2}$, are two 
[9], whereas E1 defines the input voltage gained from the PV array, and $E_{2}$ denotes the rectified DC voltage gained from WECS. $\mathrm{E}_{0}$ is the output voltage, and the load current is $\mathrm{I}_{0}$. There are four different modes of operation for this converter.

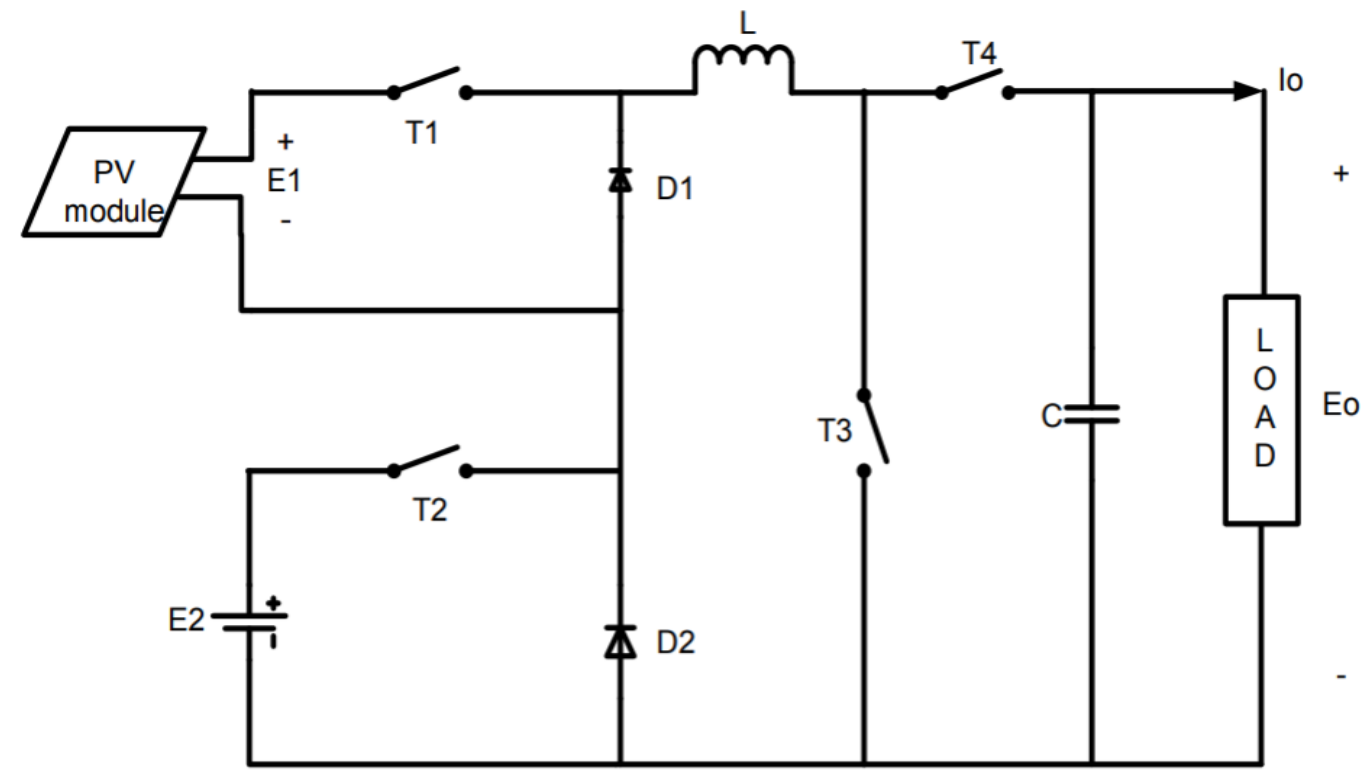

Fig.2. Dual input single output Buck-boost converter

Mode 1: In this mode, $\mathrm{E}_{1}$ supplies the transmit current towards the converter, and the inductor $\mathrm{L}$ absorbs the energy supplied by the source. Both $\mathrm{T}_{1}$ and $\mathrm{T}_{3}$ are in conduction mode.

Mode 2: This mode utilizes the energy generated from $\mathrm{E}_{2}$ (i.e., WECS). Again, L absorbs the energy completely when the switches $\mathrm{T}_{2}$ and $\mathrm{T}_{3}$ are in continuous conduction mode.

Mode 3: Both sources are activated in this mode, and the switches associated with each source, such as $\mathrm{T}_{1}, \mathrm{~T}_{2}$ and $\mathrm{T}_{3}$, are closed.

Mode 4: In the absence of both sources and switches, such as $\mathrm{T}_{1}, \mathrm{~T}_{2}$, and $\mathrm{T}_{3}$, the switch $\mathrm{T}_{4}$ starts conducting and discharges the energy stored in $\mathrm{L}$ towards $\mathrm{E}_{0}$. The capacitor $\mathrm{C}$ stores the charge and balances the load. By this way, the switching action is regulated. This cycle repeats, and the load requirement is managed. 


\section{Peak Current Mode Controller}

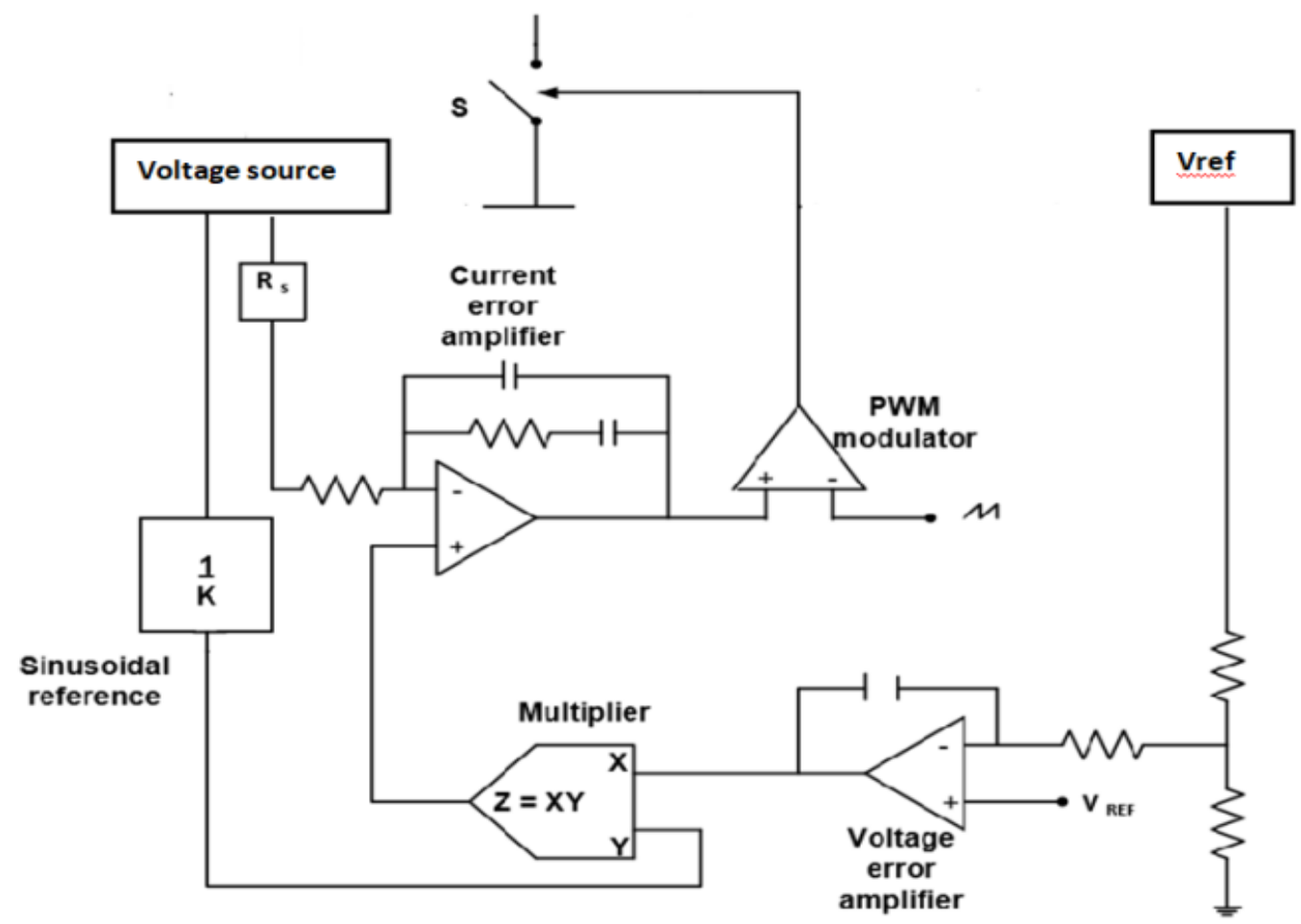

Fig.3. Closed loop control of propeller incoming voltage by suggested controller

A control technique called peak current mode control, which is shown in figure 3 , is used to turn on and off the switch in a three-phase voltage source inverter. The switch is held in an on state by a clock signal with a fixed switching frequency. The switch is turned off when the sum of the switch current and the compensating ramp equals zero. Expand the voltage error amplifier with line voltage at the rectifier to obtain the reference signal. With this extension, the current reference amplitude has been established. As a result, the switching current may rise above zero, causing the switch to conduct, or it may rise above the reference current, causing the switch to turn off.

\section{Experimental Analysis}

The experimental analysis of the proposed study is carried out in MATLAB software. A Simulink setup is implemented by the Simulink library. The PV array's temperature and irradiance are 25 degrees Celsius and 1,000, respectively. A total of 72 cells were connected in series and parallel combinations, and the voltage gain of them should be $227 \mathrm{~V}$. The speed of the rotor present in WECS is $60 \mathrm{rad} / \mathrm{s}$ and it delivers a total of $150 \mathrm{~V}$. The outcome of both resources is represented in figures 5.1 and 5.2. 


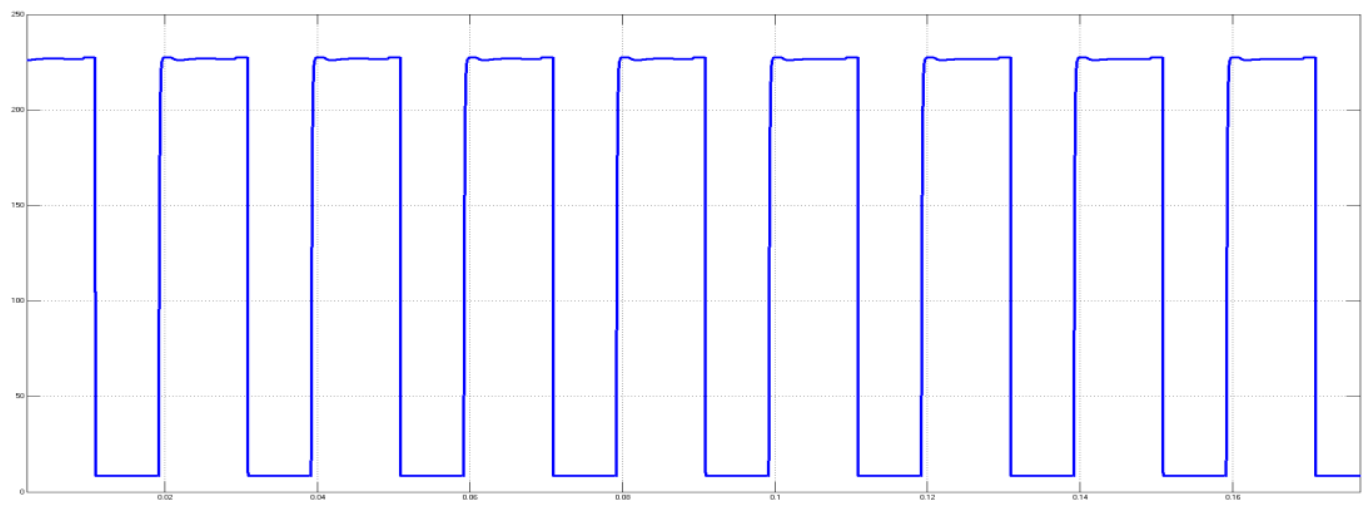

Fig.5.1. PV array's Outcome

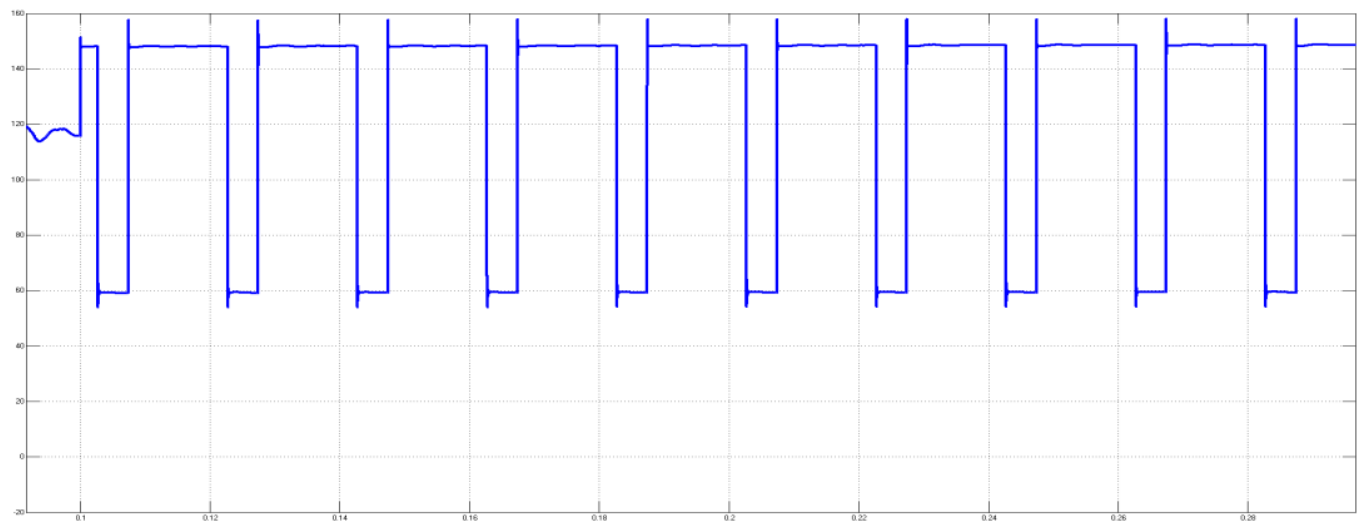

Fig.5.2. Output of WECS

The converter charges the battery and it holds $250 \mathrm{~V}$, which can be used in the future in case any voltage drops in resources or voltage lags across load.

Fig.5.3. Energy stored in battery 

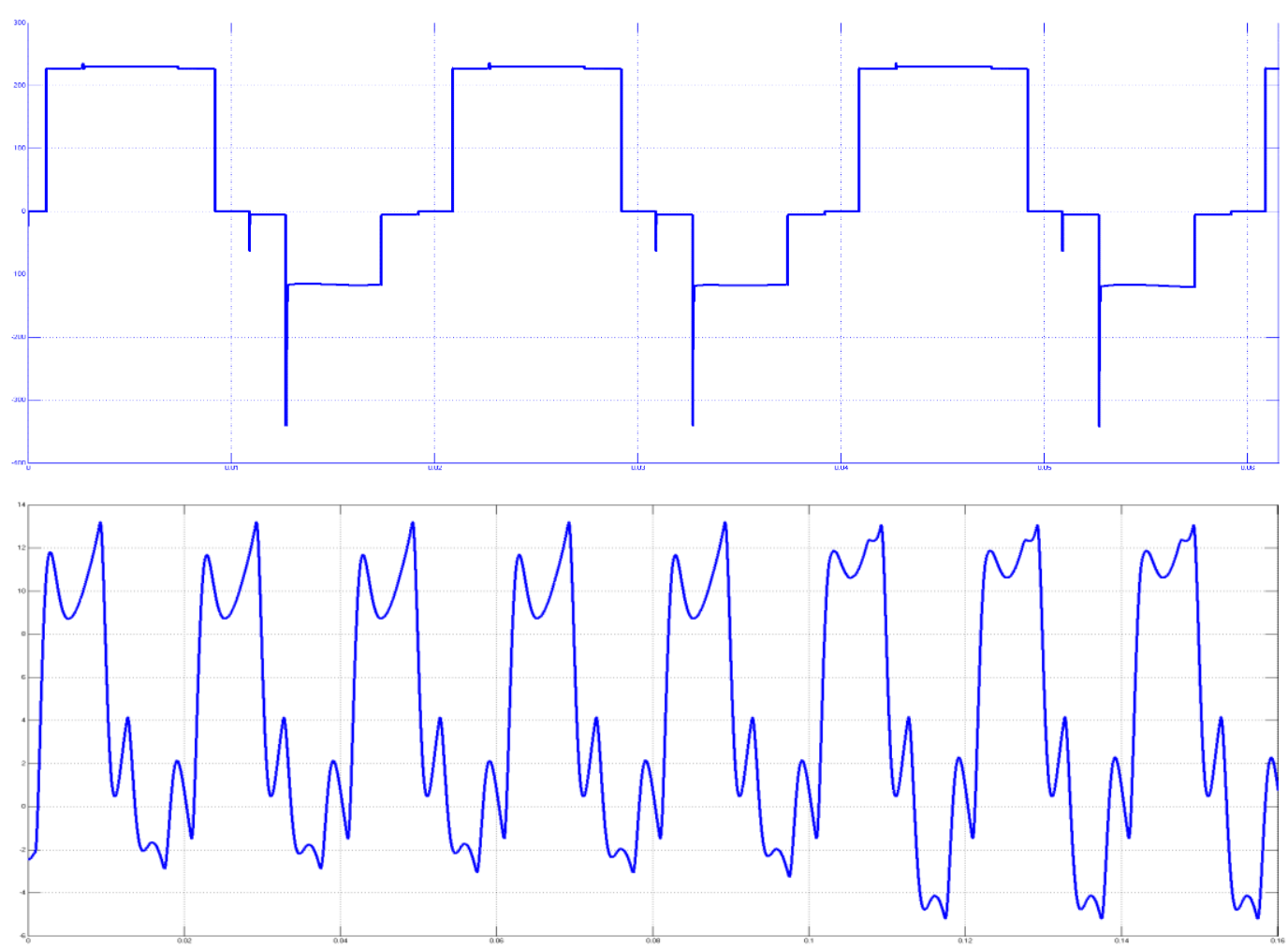

Fig.5.4. Voltage and Current across phase A

A total of $230 \mathrm{~V}$ is gained, and the above waveform depicts the amount of voltage and current supplied by the inverter's phase A terminal.

\section{Conclusion}

Thus, Renewable energy resources (solar and Wind) are hybrid with a buck boost converter to get constant output voltage. Experimental verification of the peak control mode controller is being investigated using Matlab. This mode of operation gives satisfactory speed adjustment of the propeller which is more efficient and economical. As a result of the aforementioned factors, a propeller may be able to run at a variable speed with a low starting toque.

\section{Acknowledgment}

The first author Dr. T. Sasilatha Professor and Dean sincerely acknowledges the financial assistance received from All India Council for Technical Education, India under Research Promotion Scheme. 


\section{References}

[1] T.Baldwin Immanuel, P.Rathnavel, B. Lalitha (2021). Electric Propulsion by Combination of Photovoltaic System with Induction Motor Drive. (JNxtGenTech) Vol. 1, Issue 1, June 2021

[2] R. Kumar and B. Singh, "Single stage solar PV fed brushless DC motor driven water pump," IEEE J. Emerg. Sel. Topics Power Electron., vol. 5, no. 3, pp. 1337-1385, Sep. 2017, doi: 10.1109/JESTPE.2017.2699918.

[3] Zahira, R., Lakshmi, D., \& Ravi, C. N. Power Quality Issues in Microgrid and its Solutions. Microgrid Technologies, 255.

[4] Dorothy, R., \& Sasilatha, T. (2017). System on Chip Based RTC in Power Electronics. Bulletin of Electrical Engineering and Informatics, 6(4), 358-363.

[5] S.Satish kumar and Dr M. Sasikumar (2021) "Intelligent hybrid technique for cascaded multilevel inverter based three phase grid tie hybrid power system: a WPSNN technique" Journal of Ambient Intelligence and Humanized Computing 1868-513702 Jan 2021

[6] S.Satish kumar and Dr M. Sasikumar "An Approach of Hybrid Modulation in Fusion seven-level Cascaded Multilevel Inverter accomplishment to IM drive system"2016 Second International Conference On Science Technology Engineering and Management(ICONSTEM) 978-1-5090-1706-5, pp 384-387, 2016 IEEE.

[7] Sushmita N Shetty, Md. Abdul Raheman (2017). Modelling of Dual Input DC/DC Converter for Hybrid Energy System. 2017 2nd IEEE International Conference On Recent Trends in Electronics Information \& Communication Technology (RTEICT), May 19-20, 2017, India

[8] Khaligh, A.; Jian Cao; Young-Joo Lee; , "A Multiple-Input DC-DC Converter Topology," Power Electronics, IEEE Transactions on , vol.24, no.3, pp.862-868, March 2009

[9] Ching-Jan Chen; Ching-Hsiang Cheng ; Ping-Sheng Wu ; Shinn-Shyong Wang; Unified Small-Signal Model and Compensator Design of Flyback Converter With Peak-Current Control at Variable Frequency for USB Power Delivery. IEEE Transactions on Power Electronics (Volume: 34 , Issue: 1 , Jan. 2019)

[10] R Dorothy, T Sasilatha (2017), "Smart Grid Systems Based Survey on Cyber Security Issues", Bulletin of Electrical Engineering and Informatics 6 (4), 337342

[11] S Vidhya, T Sasilatha, "Performance analysis of black hole attack detection scheme using MD5 algorithm in WSN", 2014 International Conference on Smart Structures and Systems (ICSSS), 51-54 